\title{
PARTIAL REFINEMENT OF FUNGAL CHITINASE (BEAUVERIA BASSIANA) WITH MULTISTAGE MEMBRANE FILTRATION
}

\author{
S. Mondal ${ }^{\mathrm{a}, *}$, M. BeriHun ${ }^{\mathrm{a}, \mathrm{d}}$, M. Kovacs ${ }^{\mathrm{b}}$, G. VAtai ${ }^{\mathrm{a}}$ and A. KoriS ${ }^{\mathrm{a} *}$ \\ ${ }^{\mathrm{a}}$ Department of Food Engineering, Faculty of Food Science, Szent István University, \\ H-1118 Budapest, Ménesi út 44. Hungary \\ ${ }^{b}$ Department of Microbiology, Faculty of Food Science, Szent István University, \\ H-1118 Budapest, Ménesi út 44. Hungary \\ ${ }^{c}$ Department of Chemical Engineering, Jadavpur University, 188 Raja S.C.Mullick road, Kolkata-38. India \\ ${ }^{\mathrm{d}}$ Department of Industrial Engineering, University of Salerno, via Giovanni Paolo II, 132, 84084 Fisciano SA. \\ Italy
}

(Received: 12 April 2018; accepted: 24 November 2018)

\begin{abstract}
Microscopic organisms play a vital role in the field of green technology. Among the genera fungi, the group of entomopathogens includes Beauveria bassiana, which has been found to have multifunctional applications. In this present research, we have attempted to partially purify chitinase from two strains of Beauveria bassiana (F881 and F911), each cultured in minimal media with $1 \%$ (w/v) colloidal chitin as well as in Sabouraud's dextrose media with $1 \%(\mathrm{w} / \mathrm{v})$ colloidal chitin. The purification process was done with a setup of ceramic membranes, which comprises two stages, ultrafiltration ( $50 \mathrm{~nm}$ pore size membrane) and nanofiltration (MWCO $5 \mathrm{kDa}$ ). Furthermore, with the analysis of yield of enzymatically hydrolyzed NAG (N-acetyl glucosamine), resistance and fouling of the membrane were also studied.
\end{abstract}

Keywords: Beauveria bassiana, ultrafiltration, nanofiltration, resistance, fouling, $N$-acetyl glucosamine

Though enzymatic activity has been utilized for thousands of years, only a few properties of the enzymes are understood properly. Industries use biologically active enzymes extracted from various sources of living organisms (DAHIYA et al., 2006). Microorganisms are an attractive source of enzymes, as they are cultured in large quantities in a relatively short period of time by established methods of fermentation.

The organisms are selected for production of industrially significant enzymes based on some safety criteria (ADAMs, 2004). Amongst entomopathogenic fungi, Beauveria bassiana is the most eminent one for its anti-pest activity against natural soil-borne insect pathogens, and it is currently reviewed as effective biopesticide. Chitinase, lipase, and protease enzymes degrade the cuticle of the host insect (CHARNLEY, 2003). When Beauveria bassiana comes in contact with the insect's cuticle (composed of chitin, it is commercially used in the investigation in the form of chitin flakes), it releases chitinase and breaks the polymeric chain of chitin into $\mathrm{N}$-acetyl glucosamine (GlcNAc) monomeric units. The chitin-hydrolyzing enzyme, chitinase, has gained interest in different biotechnological applications and also in food technology (KARTHIK et al., 2014). Generally, it is a white and sweet powder with a melting point of $221{ }^{\circ} \mathrm{C}$. GlcNAc and its derivatives have been employed as dietary supplements. It is possible to use chemically reformed GlcNAc as a low-cost resource for food additives, cosmetics, and pharmaceuticals in future prospects (CHEN et al., 2010).

\footnotetext{
* To whom correspondence should be addressed.

Phone: +3614826114; fax: +3614826323; e-mails: Koris.Andras@etk.szie.hu; subhoshmita@gmail.com
} 
Membrane technology, mostly ultra- and nanofiltration, has made down-stream strategy for industrial manufacture of enzymes possible. Membrane technology includes low energy requirements, hence sustainable processing; easy changing of the main critical operational variables, for instance temperature, pressure, feed flow rate, agitation, etc.; and relatively easy scale-up (BAZINET \& FiRDAOUS, 2009). Driving forces may effectively enhance membrane separation processes based upon the selective permeability of one or more components of the liquid. In such cases, the separation (ultrafiltration, microfiltration, and nanofiltration) relies on mass transport, which depends on the size of the components. In the following investigation, an attempt was made towards chitinase purification from a microbial source, specifically purification of filamentous fungal chitinase, through membrane filtration process, with crossflow ceramic membrane used in ultra- and nanofiltration.

\section{Materials and methods}

\subsection{Media and culture conditions}

Two strains of Beauveria bassiana (F881 and F911 from National Collection of Agricultural and Industrial Microorganisms, Hungary) were sub-cultured into SDA (Sabouraud's dextrose agar) medium containing dextrose $\left(40 \mathrm{~g} \mathrm{l}^{-1}\right)$, peptone $\left(10 \mathrm{~g} \mathrm{l}^{-1}\right)$, and agar $\left(10 \mathrm{~g} \mathrm{l}^{-1}\right)$. In order to prepare the SDA medium; dextrose, peptone, and agar of the above-mentioned concentrations were dissolved in 11 of distilled water. Next, the whole mixture was autoclaved along with two Petri dishes. The warm media was immediately poured into two Petri dishes under sterile conditions under laminar air flow. Excess medium was discarded immediately. The media in the two Petri dishes were allowed to cool and solidify in sterile environment. Next, two strains of Beauveria bassiana (F881 and F911) were sub-cultured into two separate petri dishes containing SDA medium and incubated at $25^{\circ} \mathrm{C}$ for 5 days in total darkness. Aftermath, one loop of spore culture of each strain from the Petri dishes was inoculated into $100 \mathrm{ml}$ Erlenmeyer flasks grown in minimal media containing $\operatorname{MgSO}_{4}\left(0.6 \mathrm{~g} \mathrm{l}^{-1}\right), \mathrm{NaCl}\left(0.5 \mathrm{~g} \mathrm{l}^{-1}\right)$, $\mathrm{FeSO}_{4} \cdot 7 \mathrm{H}_{2} \mathrm{O}\left(0.01 \mathrm{~g} \mathrm{l}^{-1}\right), \mathrm{ZnSO}_{4}\left(0.01 \mathrm{~g} \mathrm{l}^{-1}\right), \mathrm{KH}_{2} \mathrm{PO}_{4}\left(1.0 \mathrm{~g} \mathrm{l}^{-1}\right)$ with $1 \%$ colloidal chitin. There were two duplicate flasks incubated at $25^{\circ} \mathrm{C}$ without shaking for 5 days in total darkness to be used for the screening method for chitinase production.

\subsection{Screening for chitinase and degradation of chitin in CCA (colloidal chitin agar) plates}

The strains of Beauveria bassiana (F881 and F911) were grown in minimal medium containing $1 \%$ colloidal chitin, and were incubated at $25{ }^{\circ} \mathrm{C}$ for 5 days. After 5 days of incubation, the cultures were harvested, centrifuged (Ultracentrifuge 1230D Scitec, China) at 1000 r.p.m. for $15 \mathrm{~min}$ at $4{ }^{\circ} \mathrm{C}$, and the supernatant was collected. Colloidal chitin agar plates were prepared. Membrane filter discs $(0.45 \mu \mathrm{m})$ were dipped in the culture filtrate and were placed onto the agar surface and incubated at $25^{\circ} \mathrm{C}$ for 5 days. The development of clear zone around the disc was observed.

\subsection{Membrane process operation}

In the present study, ceramic membranes (Pall, Membralox T1-07 modules, with an active filtration area of $0.005 \mathrm{~m}^{2}$ ) fitted in a membrane housing with cross-flow filtration process attached to a feed tank, and two pressure meters and valves to control the flow rate checked by a flow meter, were used. The flux relates directly to driving force (i.e. transmembrane

Acta Alimentaria 48, 2019 
pressure (TMP) for conventional membrane modules) and total hydraulic resistance exerted by the membrane and the adjacent interfacial section. While for conventional biomass separation in membrane modules the driving force for the process is the transmembrane pressure, in extractive or diffusive separations in membrane modules the driving force is the concentration, or rather the partial pressure, gradient (BowEN et al., 1995; JIMENEZ et al., 2009). The permeate flux declines because of the irreversible fouling due to usage. This mechanism could be expressed by the difference in total membrane resistance, $\mathrm{R}_{\mathrm{T}}\left(\mathrm{m}^{-1}\right)$, between new and the used membranes by using Darcy's law:

$$
\mathrm{J}=\frac{\Delta \mathrm{P}}{\mu \mathrm{R}_{\mathrm{T}}}=\frac{\Delta \mathrm{P}}{\mu\left(\mathrm{R}_{\mathrm{m}}+\mathrm{R}_{\mathrm{f}}\right)}
$$

where $\mathrm{J}$ is the permeate flux $\left(\mathrm{m}^{3} \mathrm{~m}^{-2} \mathrm{~s}^{-1}\right), \mu$ is the viscosity of the permeate stream $\left(\left(\mathrm{kg} \mathrm{m}^{-1} \mathrm{~s}^{-1}\right)\right.$; $\Delta \mathrm{P}$ is the transmembrane pressure (bar); $\mathrm{R}_{\mathrm{m}}$ is the intrinsic (clean) membrane resistance $\left(\mathrm{m}^{-1}\right)$ for water flow, and $R_{f}$ is the fouling resistance. The intrinsic membrane resistance, $R_{m}$, was calculated as

$$
\mathrm{R}_{\mathrm{m}}=\frac{\Delta \mathrm{P}}{\mu_{\mathrm{w}} \mathrm{J}_{\mathrm{w}}}
$$

where $\mu_{w}$ is the water viscosity and $\mathrm{J}_{\mathrm{w}}$ is the permeate flux of the clean membrane. Following this, the chitinase extract was filtrated and the permeate flux was recorded during the whole process. Total membrane resistance, $\mathrm{R}_{\mathrm{T}}$ was calculated as

$$
\mathrm{R}_{\mathrm{T}}=\frac{\Delta \mathrm{P}}{\mu_{\mathrm{s}} \mathrm{J}_{\mathrm{s}}}
$$

where the $\mu_{\mathrm{s}}$ is the solution viscosity and $\mathrm{J}_{\mathrm{s}}$ is the permeate flux of the solute in the membrane during the filtration. Then, the membrane was flushed with deionized water immediately after the experiment, and the fouling resistance was determined as

$$
\mathrm{R}_{\mathrm{f}}=\frac{\Delta \mathrm{P}}{\mu_{\mathrm{w}} \mathrm{J}_{\mathrm{s}}}-\mathrm{R}_{\mathrm{m}}
$$

where $\mu_{\mathrm{w}}$ is the water viscosity and $\mathrm{J}_{\mathrm{s}}$ is the permeate flux. The hydraulic permeability of the membrane was determined from $R_{\mathrm{f}}=R_{\mathrm{fm}}-R_{\mathrm{m}}$, where $R_{\mathrm{fm}}$ is calculated as, being the membrane resistance after the chitinase filtration experiment followed by mild cleaning.

On the other hand, the sub-cultured strains of Beauveria bassiana were grown later in SDY (Sabouraud's dextrose yeast), liquid broth culture media used as feed for membrane filtration experiments. Ultrafiltration experiments were performed in a cross-flow filtration unit. The chitinase was extracted from Beauveria bassiana (F881 and F911) grown in 4 different samples (each grown in SDY medium, SDY medium with chitin, minimal medium (MM), and minimal medium with chitin). These were filtered through a $50 \mathrm{~nm}$ pore sized tubular ceramic membrane at a constant pressure of 3 bar and flow rate of $41.66 \mathrm{ml} \mathrm{s}^{-1}$, followed by cross-flow nanofiltration operation performed with a ceramic membrane with nominal molecular cut off (MWCO) of $5 \mathrm{kDa}$ at 3 bar. The molecular weight range of filamentous fungal chitinase was considered 30-170 kDa (including Group C with chitin binding domain) from literature survey (XIAO et al., 2012). Also, the microscopic analysis showed that the conidial diameter of the strain was $2.32 \mu \mathrm{m}$. For this reason, in the first membrane filtration, $50 \mathrm{~nm}$ pore size membrane was selected in order to purify the biomass 
of the Beauveria bassiana with the aim of concentrating the enzyme in the permeate stream. In the next filtration step, $5 \mathrm{kDa}$ membrane was used to retain the enzyme within the considered range and to produce concentrated protein solution in the retentate stream.

In the first experiment, permeate was collected from the filtration unit with $50 \mathrm{~nm}$ membrane filtration, which was used as feed in the second nanofiltration step with $5 \mathrm{kDa}$ membrane kept at $20{ }^{\circ} \mathrm{C}$. The initial volume of feed solution was $600 \mathrm{ml}$ for each sample. Before the purification of the sample, to standardize the membrane, it was cleaned and pure water permeability (PWP) was measured at different operating pressures (1-5 bar) at $20^{\circ} \mathrm{C}$. Prior to the first UF, Beauveria bassiana biomass was removed by centrifugation to eliminate large solid aggregates, thus preventing the system from membrane fouling. During sample purification on each pore size membrane, the permeate volumes of cross-flow ceramic membrane module were collected at constant time intervals, and the permeate flux was calculated according to

$$
\mathrm{J}=\frac{\mathrm{V}}{\mathrm{A} * \mathrm{t}}
$$

where $J$ is the permeate flux $\left(\mathrm{m}^{3} \mathrm{~m}^{-2} \mathrm{~s}^{-1}\right), \mathrm{V}$ is the permeate volume $\left(\mathrm{m}^{3}\right), \mathrm{A}$ is the effective membrane area $\left(\mathrm{m}^{2}\right)$, and $\mathrm{t}$ is the time (s). After each experiment, the membrane was cleaned by sequentially using $0.2 \%(\mathrm{~m} / \mathrm{m})$ Ultrasil (Ecolab, Hungary), $0.1 \%(\mathrm{~m} / \mathrm{m})$ citric acid and $0.1 \%(\mathrm{~m} / \mathrm{m}) \mathrm{NaOH}$ solution one by one and rinsed with deionized water for $30 \mathrm{~min}$ after each washing media.

\subsection{Crossflow membrane module}

Figure 1 represents the process flow sheet for chitinase production using multistage membrane filtration. The sample feedstock was fed to the sample tank. First, this passed through nanofiltration with the retentate in continuous process. In the next step, the permeate from nanofiltration went through ultrafiltration with its retentate stream as the final extracted enzyme. This was further analysed for yield percentage.

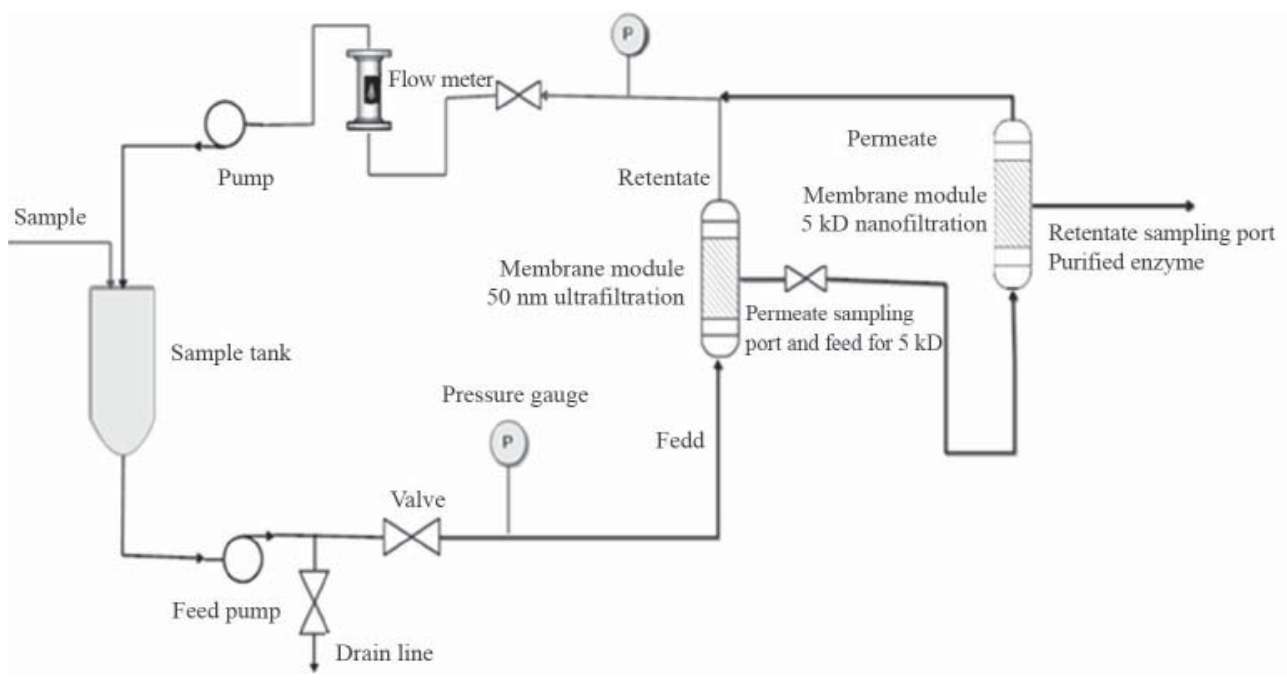

Fig. 1. The membrane purification module for chitinase production 


\section{Results and discussion}

\subsection{Membrane compaction and water run}

In each case, the water flux was found to regain $98 \%$ of its original value, suggesting the cause of flux decline to be due to reversible fouling layers. This was proved by $\mathrm{R}^{2}=0.996$ to 0.994 (in case of $50 \mathrm{~nm}$ PWP) and $\mathrm{R}^{2}=0.999$ to 0.994 (in case of $5 \mathrm{kDa}$ PWP). The fouling of the membrane was compared to pure water permeability of standardized membrane at transmembrane pressure of 1-5 bar (Figs 2 and 3). There was an average fouling of approx. $39.14 \%$ and $16.02 \%$ observed in the successive membranes of $50 \mathrm{~nm}$ pore size and $5 \mathrm{kDa}$ (MWCO), respectively. This was calculated both for $50 \mathrm{~nm}$ and $5 \mathrm{kDa}$ (MWCO) as (average flux of water after every filtration/PWP) $\times 100 \%$

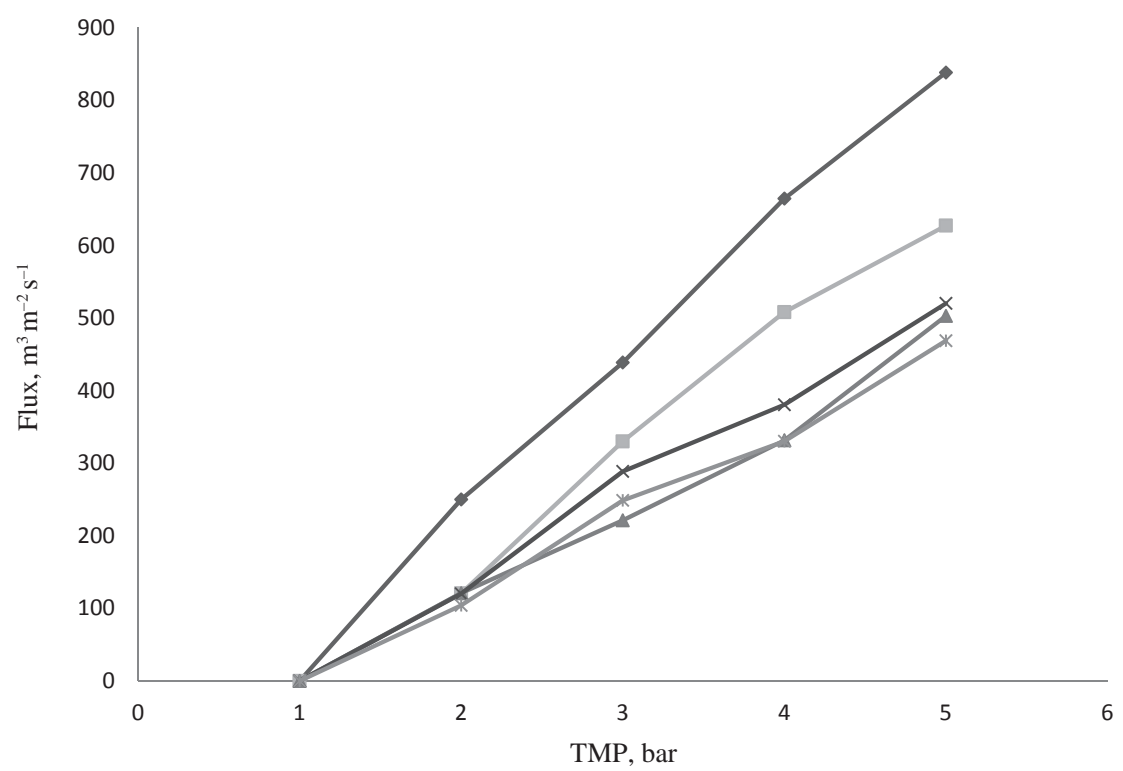

Fig. 2. Performance of the $50 \mathrm{~nm}$ pore size membrane in fouling with respect to standardized pure water permeability PWP: pure water permeability; F8: F881 strain; F9: F991 strain; MM: minimal media; SDY: Sabouraud's dextrose yeast

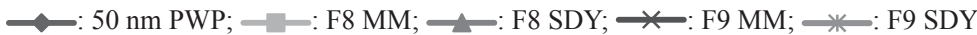




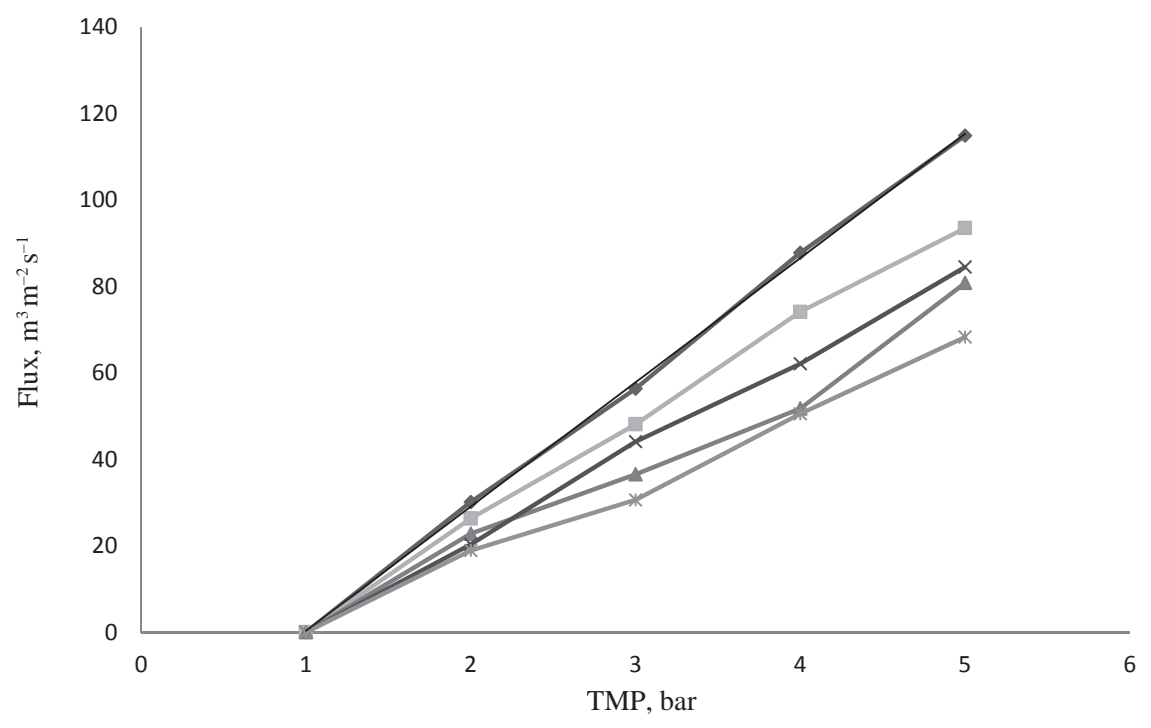

Fig. 3. Performance of the $5 \mathrm{kDa}$ MWCO membrane in fouling with respect to standardized PWP abbreviations: see Fig. 2 .

: 50 nm PWP.

F8 MM; —-: F8 SDY

F9 MM; — F9 SDY

\subsection{Resistance analysis}

Prior to the experiments, the membrane was subjected to compaction for about an hour with de-ionized water at a pressure of $5 \mathrm{bar}$, higher than the highest operating pressure to prevent any possibility of a change of membrane hydraulic resistance. Once the water flux became steady with no further decrease, it was concluded that full compaction of the membrane had taken place. After compaction, the membrane hydraulic resistance $\left(\mathrm{R}_{\mathrm{m}}\right)$ was determined based on water run at different TMPs (1-5 bar). With the consideration of Equations $1-4, \mathrm{R}_{\mathrm{m}}$ was calculated for ultrafiltration and nanofiltration membranes before using them for filtration of samples. In case of ultrafiltration, the obtained value of $\mathrm{R}_{\mathrm{m}}$ was more than twice higher than the $R_{f}$ in each combination (Fig. 4). In case of nanofiltration, the $R_{m}$ value was about 6 times higher than $\mathrm{R}_{\mathrm{f}}$ in case of strain F881 in SDY and strain F881 in MM, described the reversible phenomenon that does not affect the intrinsic properties of the membrane. A reduced fouling formation is observed during ultrafiltration of F881 (MM) and F911 (MM), along with nanofiltration of F881 (MM) and F881 (SDY), makes the scaling up of enzyme purification more attractive. Among all the samples, the ratio $R_{f} / R_{T}$ was highest in the F881 (MM) during ultrafiltration and lowest during nanofiltration of F911 (SDY) 12.11 and 2.186, respectively. 


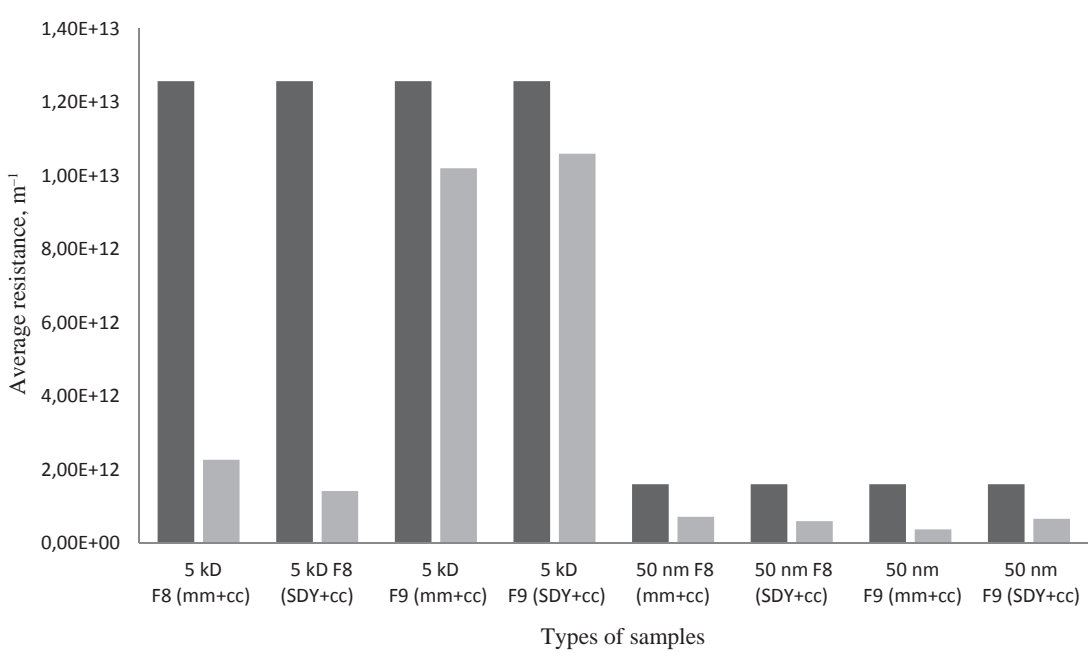

Fig. 4. Resistance of the membranes ( $5 \mathrm{kD} \mathrm{MWCO}$ and $50 \mathrm{~nm})$

5 kD: nanofiltration; 50 nm: ultrafiltration; F8: F881 strain; F9: F991 strain; MM: minimal media;

SDY: Sabouraud's dextrose yeast; cc: colloidal chitin

ㄷ: $\mathrm{R}_{\mathrm{m}}=\mathrm{TMP} / \mu_{\mathrm{w}} \times$ Flux $\left(\mathrm{m}^{-1}\right) ;:: \mathrm{R}_{\mathrm{f}}=\left[\mathrm{TMP} / \mu_{\text {solute }} \times\right.$ Flux $\left.\left(\mathrm{m}^{-1}\right)\right]-\mathrm{R}_{\mathrm{m}}$

\subsection{Multistage membrane separation and hydrodynamic study of membrane}

Permeate volumes were collected at constant time intervals and permeate flux $\mathrm{J}$ was calculated on the basis of Eq. 6. In Figure 5 it can be observed that permeate flux decreased gradually with the increase of time for different samples, and it becomes almost constant at 0.01 $\mathrm{m}^{3} \mathrm{~m}^{-2} \mathrm{~s}^{-1}$, in each case. For samples F911 and F881 minimal medium with $1 \%(\mathrm{w} / \mathrm{v})$ colloidal chitin showed high flux at the starting point, whereas medium SDY with $1 \%(\mathrm{w} / \mathrm{v})$ colloidal chitin showed lower flux $0.02 \mathrm{~m}^{3} \mathrm{~m}^{-2} \mathrm{~s}^{-1}$ from the beginning, probably due to the higher density of the feed. The permeate flux declined with time, which is a typical feature of pressure driven processes. Figure 6 reports flux ranging from 0.01 to $0.002 \mathrm{~m}^{3} \mathrm{~m}^{-2} \mathrm{~s}^{-1}$ at nanofiltration stage. 


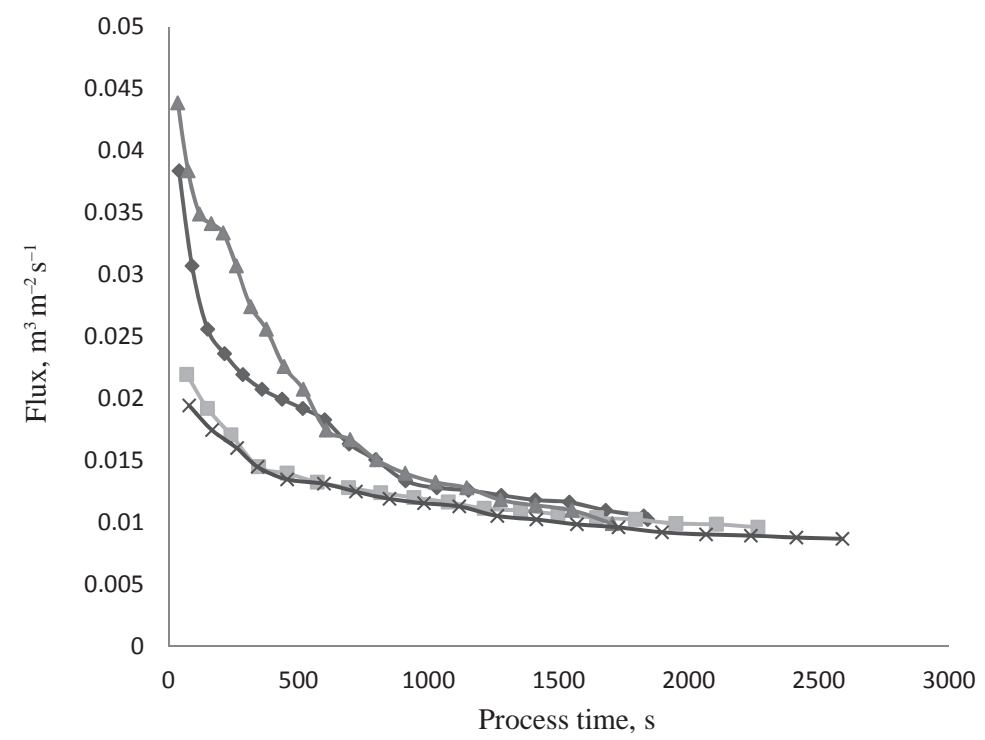

Fig. 5. Process time history of permeate flux for different samples with $50 \mathrm{~nm}$ membrane pore size : F8 mm+cc; - F8 SDY; $\longrightarrow$ F9 mm+cc; $\leftarrow$ : F9 SDY

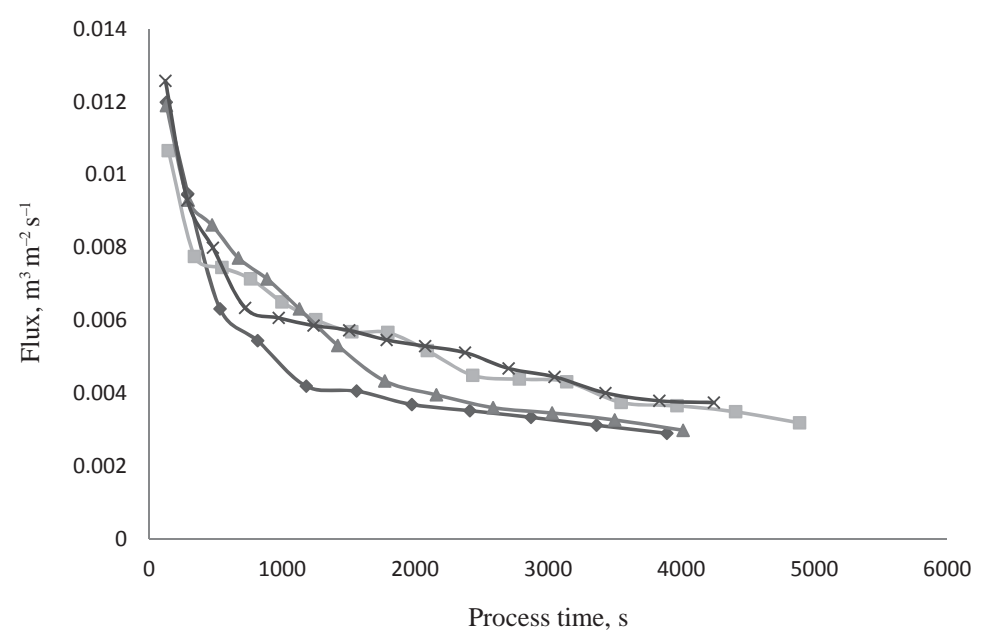

Fig. 6. Process time history of permeate flux for different samples with $5 \mathrm{kDa}$ membrane $\longrightarrow$ :F8 mm+cc; - - F8 SDY; $\longrightarrow$ F9 mm+cc; $\leftarrow$ : F9 SDY

\subsection{Production and yield of hydrolyzed $N$-acetyl glucosamine}

The membrane purified chitinase in form of hydrolyzed chitin (NAG) was measured by HPLC (C18 130 A LC Column $250 \times 4.6 \mathrm{~mm})$ calibrated with standard of NAG at a retention 
time of $2 \mathrm{~min}$. Analysis was carried out using acetonitrile:water $(70: 30 \mathrm{v} / \mathrm{v})$ as mobile phase at a flow rate of $1.0 \mathrm{ml} \mathrm{min}^{-1}$ and UV detection at $210 \mathrm{~nm}$. The yield of GlcNAc was calculated by the following equation (DuNCAN et al., 2003):

Yield $(\%)=[$ GlcNAc produced mol/repeating unit of chitin (mol) added $] \times 100$

The strain Beauveria bassiana F881 grown in minimal medium with 1\% (w/v) colloidal chitin showed higher yield of NAG in the retentate after the second stage of filtration. But Beauveria bassiana F911 grown in SDY media with $1 \%(\mathrm{w} / \mathrm{v})$ colloidal chitin yielded more NAG in the permeate stream after the first stage of filtration. The strain F911 gave no good results when grown in minimal medium (Fig. 7).

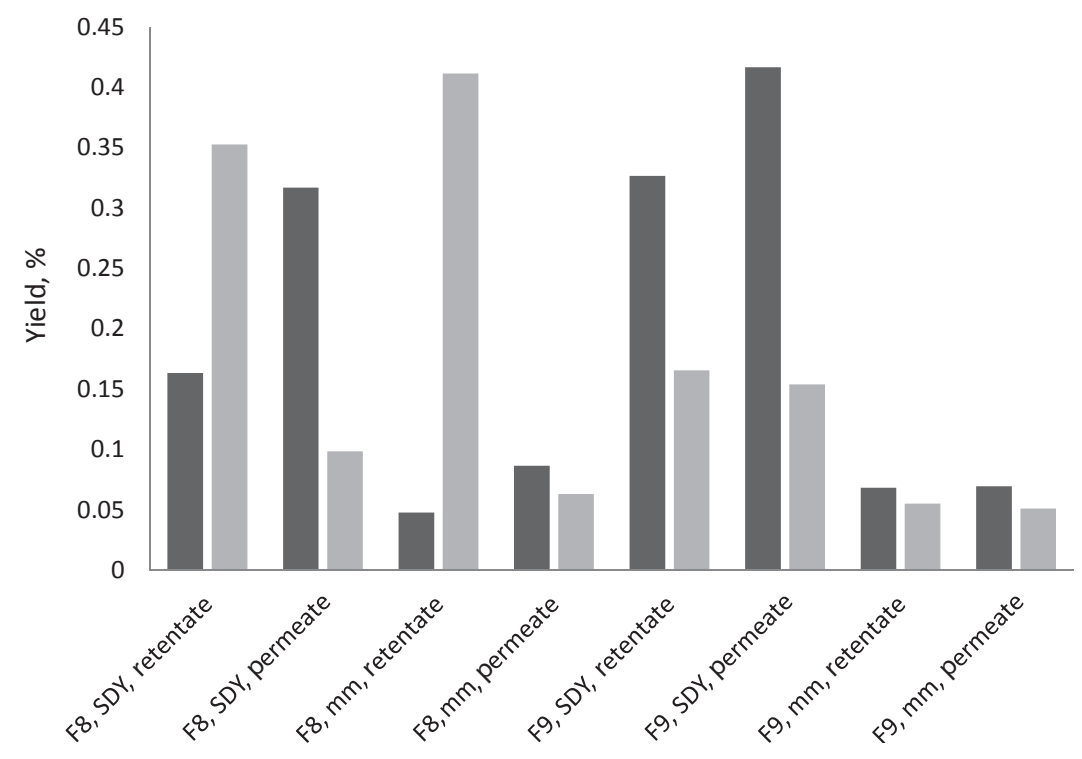

Fig. 7. Yields of GlcNAc produced in 45 min by membrane filtration of different samples of Beauveria bassiana F881 and F911 cultivated in SDY and minimal media

ㄷ: $50 \mathrm{~nm}$ (ultrafiltration); $: 5 \mathrm{kD}$ (nanofiltration)

\subsection{SDS-PAGE for high yield sample}

To know the size and purity of the chitinase obtained, the sample with the highest yield (F881 minimal medium retentate from ultrafiltration) was quantified through SDS-PAGE. For the determination, $8 \%$ resolving gel and $4 \%$ stacking gel was prepared. Three microlitres of ladder and the sample were mixed with loading dye and $\beta$-mercaptoethanol. The mixture of the sample was heated for $1 \mathrm{~min}$ at $90^{\circ} \mathrm{C}$ before loading. The gel was run at $250 \mathrm{~V}$ for $45 \mathrm{~min}$, then was stained with coomassie blue with addition of $10 \%$ acetic acid for fixation. After staining overnight, the gel was de-stained to obtain the protein band (Fig. 8). 


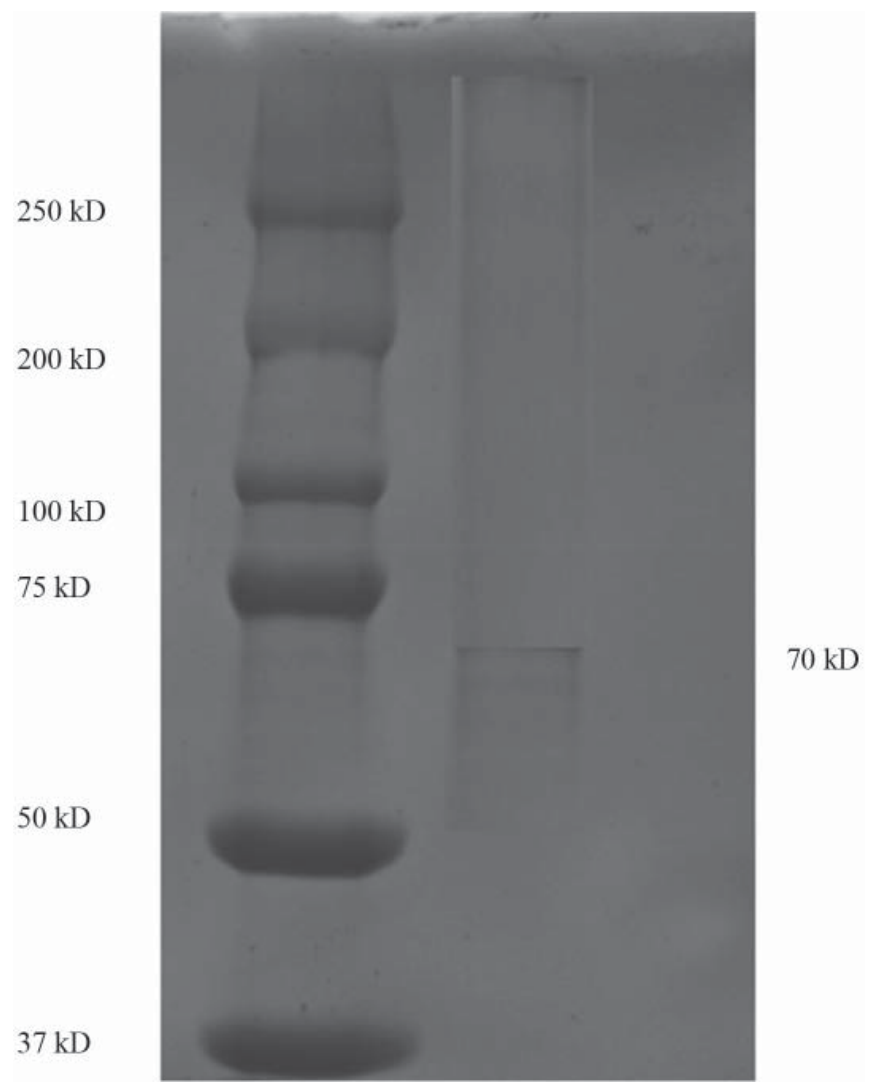

Fig. 8. SDS-PAGE of chitinase from Beauveria bassiana F881 (minimal medium) after ultrafiltration

\section{Conclusions}

In the present investigation, filamentous fungal chitinase has been partially purified. It was found that decline of the permeate flux at the UF stage was higher in case of Beauveria bassiana F911 and F881 grown in minimal medium with 1\%(w/v) colloidal chitin than in SDY medium. On the other hand, in case of nanofiltration, all samples showed close permeate flux values. The experimental evaluations of resistances for membrane compaction showed that $R_{m}$ values in case of ultra- and nanofiltration were two and six times higher than $R_{f}$, respectively. Finally, amounts of hydrolysed chitin determined with HPLC method indicated that optimal enzymatic bioconversion yield from Beauveria bassiana F881 grown in minimal medium with $1 \%(\mathrm{w} / \mathrm{v})$ colloidal chitin in the retentate stream was obtained after nanofiltration.

All authors are grateful to Stipendium Hungaricum scholarship grant (for partial Ph.D. program) for financial support to carry out this research. 


\section{References}

Adams, D.J. (2004): Fungal cell wall chitinases and glucanases. Microbiology, 150, 2029-2035.

Bazinet, L. \& Firdaous, L. (2009): Membrane processes and devices for separation of bioactive peptides. Recent Pat. Biotechnol., 3, 61-72.

Bowen, W.R., Calvo, J.I. \& Hernadez, A. (1995): Steps of membrane blocking in flux decline during protein microfiltration. J. Membrane Sci., 101, 153-165.

Charnley, A.K. (2003): Fungal pathogens of insects: Cuticle-degrading enzymes and toxins. Adv. Bot. Res., 40, 241-321.

Chen, J.K., Shen, C.R. \& Liu, C.L. (2010): N-Acetylglucosamine: Production and applications. Mar. Drugs, 8(9), 2493-2516.

Dahiya, N., Tewari, R. \& Hoondlal, G.S. (2006): Biotechnological aspects of chitinolytic enzymes: A review. Appl. Microbiol. Biot., 71(6), 773-782.

Duncan, S.M., Minasaki, R., Farrell, R.L., Thwaites, J.M., Held, B.W. .. \& A Aiba, S. (2003): Enzymatic production of N-acetyl-D-glucosamine from chitin: Degradation study of $\mathrm{N}$-acetylchitooligosaccharide and the effect of mixing of crude enzymes. Carbohyd. Polym., 51, 391-395.

Jimenez, M.P., Jonsson, G.E. \& Meyer, A.S. (2009): Membrane technology for purification of enzymatically produced oligosaccharides: Molecular and operational features affecting performance. Sep. Purif. Technol., $70,1-11$.

Karthik, N., Akansha, K., Parameshwaran, B. \& Pandey, A. (2014): Production, purification and properties of fungal chitinases - a review. Indian J. Exp. Biol., 52, 1025-1035.

XiaO, G., Ying, S.H., Zheng, P., Wang, Z.L., Zhang, S. .. \& F Feng, M.G. (2012): Genomic perspectives on the evolution of fungal entomopathogenicity in Beauveria bassiana. Sci. Rep - UK., 2, 483.

Open Acces statement. This is an open-access article distributed under the terms of the Creative Commons Attribution 4.0 International License (https://creativecommons.org/licenses/by/4.0/), which permits unrestricted use, distribution, and reproduction in any medium, provided the original author and source are credited, a link to the CC License is provided, and changes - if any - are indicated. (SID_1) 